\title{
EDITORIAL
}

\section{Alcoholism as a disease}

There must be something wrong somewhere, when a well-known psychiatrist and his colleagues report painstaking research over several years (Winokur, 1971) into the question of whether alcoholism is three diseases or one, while another asserts trenchantly that it is not a disease at all, simply a bad habit (Szasz, 1972).

This is not just hairsplitting. Because alcoholism is thought of in the United States of America as so clearly a disease, some 16 States have by now passed laws which mean that public drunkenness is no longer an offence, and the police van now drives the patient to a 'detoxification centre', instead of, as formerly, taking the prisoner to a police cell.

Presumably, some time spent examining the meaning of the words 'alcoholism' and 'disease' would be rewarding, but the confusion in the minds of those who use these words is reflected in the plethora of definitions. Keller (1958) pointed out that there were 30 definitions of the word alcoholism extant in 1942. Ignoring the many others that have appeared since, and assuming only three definitions of the word 'disease' (which must be a very conservative estimate), it would follow that one would need to assemble about 90 doctors to debate the present topic to make it likely that at least two would understand each other.

Acute intoxication (drunkenness) is a self-limiting, brief diseased state but it need not be considered here, where chronic intoxication (in the pharmacological sense) is the issue.

A practical approach to the problem might be to look at those kinds of alcoholism on which there is general clinical agreement, against a concept of disease which is equally generally acceptable. Thus all those conditions with a demonstrable pathological basis (cirrhosis of the liver, pancreatitis, gastritis, polyneuropathy, for example), which follow the ingestion of large quantities of alcohol, are clearly diseased states and need not be considered further.

All those who accept that there are mental diseases (schizophrenia, manic-depressive psychosis) will have no difficulty in accepting, say, alcoholic hallucinosis as a disease, even if no pathological changes in the tissues of those so affected can be demonstrated.

That certain diseases of mind or body are the result of heavy drinking is, therefore, not to be denied. Where, then, are the doubtful areas? One such is uncomplicated dependency on alcohol. To understand this, one must go back a little into the history of certain words.

An early definition of drug addiction, quoted by an expert committee of the World Health Organization (1951), read as follows:

'Drug addiction is a state of periodic or chronic intoxication, detrimental to the individual and to society produced by the repeated consumption of a drug (natural or synthetic). Its characteristics include:

1. An overpowering desire or need (compulsion) to continue taking the drug and to obtain it by any means;

2. A tendency to increase the dose;

3. A psychic (psychological) and sometimes a physical dependence on the effects of the drug.'

At a later date, the World Health Organization (1964) recommended that the word 'addiction' be replaced by the word 'dependency', and more recently, in 1969, set out a new definition of dependency that ran as follows:

'A state, psychic and sometimes also physical, resulting from the interaction between a living organism and a drug, characterised by behavioural and other responses that always include a compulsion to take the drug on a continuous or periodic basis in order to experience its psychic effects, and sometimes to avoid the 
discomfort of its absence. Tolerance may or may not be present. A person may be dependent on more than onc drug.

In psychiatry, the word 'compulsion' has a special meaning, implying that the tendency to carry out the action concerned is recognized by the subject as something alien to himself-that is, that it is morbid. The sufferer's attitude is summed up in the words 'It is silly, but I can't help it', which contrasts with the mental attitude of most alcoholics.

If one allows the word 'compulsion' in both the definitions given above, then one is begging the question as to whether drug dependence (addiction) is or is not a disease.

In order to leave us free to look at dependency in the context of health or disease, it is suggested that we use a neutral word like 'urge' wherever 'compulsion' is used by WHO.

It is interesting to see what that body dropped from the earlier definition. There is no longer any reference to harm, whether to the individual concerned or to others, and no insistence on tolerance. What is retained is essentially an urge, whether to achieve simply a psychic effect (psychological dependence) or to relieve physical withdrawal symptoms (physical dependence).

Now, however he has arrived at that condition, the man who is reduced to a trembling, shuddering state of misery by withdrawal of his alcohol is as much ill as if his physical function were disturbed in the direction of vomiting, diarrhoea, gooseflesh, sneezing, or any of the other disorders of function which are seen in withdrawal of one or other narcotic drug.

How then about the man who is only psychically dependent on alcohol? Here is the rub. We know that the urge to go on taking a drug of dependence can be tremendously powerful, which is certainly the case with alcohol in some people. It is not always so, however. There seems to be no reason why in some men this urge should not be much less pronounced, so that the individual concerned can cope with it, albeit at the price of some discomfort.

According to Seevers (1968), the majority of the world population is dependent on one or other psychoactive drug. Accepting that dependence is now defined as harmless, there is little point in stretching the concept of illness to include so many people, many of whom would earlier have been called 'stabilized addicts' (Brain, 1961). When, as seems clear, quantity and frequency of drug ingestion (Seevers, 1968) and of alcohol ingestion (De Lint and Schmidt, 1971) are key pharmacological factors in the genesis of dependence, and drinking in particular is determined by sociological factors (Bales, 1946) as well as by psychological processes normal to learning behaviour, the case for regarding psychological dependence as an illness virtually disappears. If anything is needed to clinch this view, it is the wording of some definitions put forward by those who feel most strongly that alcoholism is a disease, when they preface the word 'dependence' by the adjective 'pathological' (National Council on Alcoholism, 1972) in their formulations.

Wikler (1971), who acknowledges the likely development of dependence as the outcome of the operation of the normal laws of psychological (and social) functioning, also finds that the term 'compulsion' is a hindrance to clear thinking on this topic. Forced to re-define drug dependence, he brings in to his definition 'the degree that (it) creates a medical problem in treatment', which again begs the question under discussion here.

The truth is that Winokur and Szasz are both right, as far as the instances of alcoholism with which they separately deal are concerned, and are both wrong if they generalize to include all the manifestations of alcoholism.

Then why the fuss? Presumably, it is because of what follows from these apparently contradictory views. Calling alcoholism a disease has certainly made society more tolerant towards alcoholics, and perhaps more willing to help them, though this says more about the shortcomings of society than of alcoholics.

Against this, calling alcoholism a disease has clearly led many people to look for pathognomonic signs such as a particular pattern of drinking, as when Keller (1960) writes:

'the significance of loss of control is that it denotes helpless dependence or addiction, the essence of the disease' 
Calling alcoholism a disease also encourages the tendency to look for a progression of symptoms, leading to a depressing catalogue of behavioural changes in which physical, mental, and social events assume an improbable sequence, owing more to impressionistic than scientific evidence.

These two consequences of 'the disease concept of alcoholism' are largely to blame for the failure of doctors to recognize the condition at an early stage. As Blane et al. (1963) state,

'socially intact alcoholics are not referred by physicians for specialised treatment of alcoholism despite the fact that their prognosis is relatively good ... large segments of the population go untreated until their members reach social stages of the disease that coincide with the physicians' limited expectations of what alcoholism is'.

Most doctors recognize only the late case, dismissing the others as 'not true alcoholics', or as 'excessive drinkers' or 'problem drinkers', simply because of the absence of a 'progression of symptoms' or 'pathognomonic signs'.

Instead, they would do better to have a broad concept of alcoholism as any intermittent or continual drinking which results in dependency or physical, mental, or social harm.

While the psychologically dependent alcoholic, with nothing else to show for his condition, would be outside this bracket for therapeutic purposes, he would be very much the concern of medicine (and society) for preventive purposes, since it is highly likely that a great many of those who now present for treatment have gone through this earlier phase.

To call alcoholism a disease does not do justice to the complexities of the problem, and, by ordering medical thought along the lines of symptoms and signs, it is largely to blame for the late recognition of this condition. It militates against a shift of emphasis to the non-disease state of (harmless) dependence, where preventive measures of a social kind may be the most effective in the long run. Two other unfortunate consequences of 'the disease concept' might be mentioned. One is the way that research into alcoholism tends to focus on metabolic-usually hepatic, for some strange reason-processes rather than on the social and psychological conditions which favour high consumption of alcohol. The other is that it needlessly confuses the non-medical, professional people who are concerned with helping alcoholics, who detect a note of ambivalence in the medical man when he declares that alcoholics are sick, and then is mysteriously selective in the help he appears to be able to offer, and whose treatment begins by expecting 'the patient' to forsake his 'symptoms'.

Perhaps we should stop saying 'alcoholism is a disease'-and get on with the job of helping alcoholics where we can.

D. L. DAVIES

\section{REFERENCES}

Bales, R. F. (1946). Cultural differences in rates of alcoholism. Quarterly Journal of Siudies on Alcohol, 6, 480-499.

Blane, H. T., Overton, W. F. Jr., and Chafetz, M. E. (1963). Social factors in the diagnosis of alcoholism. 1. Characteristics of the patient. Quarterly Journal of Studies on Alcohol, 24, 640-663.

De Lint, J., and Schmidt, W. (1971). Consumption averages and alcoholism prevalence; a brief review of epidemiological investigations. British Journal of Addiction, 66, 97107.

Keller, M. (1958). Alcoholism: nature and extent of the problem. Annals of the American Academy of Political and Social Science, 315, 1-11.

Keller, M. (1960). The definition of alcoholism. Quarterly Journal of Studies on Alcohol, 21, 125-134.

National Council on Alcoholism (1972). Criteria for the diagnosis of alcoholism. American Journal of Psychiatry, 129, 127-135.
Seevers, M. H. (1968). Psychopharmacological elements of drug dependence. Journal of the American Medical Association, 206, 1263-1266.

Szasz, T. S. (1972). Bad habits are not diseases. A refutation of the claim that alcoholism is a disease. Lancet, 2, 83-84.

Wikler, A. (1971). Present status of the concept of drug dependence. Psychological Medicine, 1, 377-380.

Winokur, G., Rimmer, J., and Reich, T. (1971). Alcoholism IV. Is there more than one type of alcoholism? British Journal of Psychiatry, 118, 525-531.

World Health Organization (1951). Expert Committee on Mental Health Technical Report Series. No. 42. WHO: Geneva.

World Health Organization (1964). Expert Committee on Addiction-Producing Drugs. Thirteenth report. Technical Report Series, No. 273. WHO: Geneva.

World Health Organization (1969). Expert Committee on Drug Dependence. Sixteenth report. Technical Report Series, No. 407. WHO: Geneva. 